\title{
Policies and practices on competing interests of academic staff in Australian universities
}

\section{Simon Chapman \\ Professor of Public Health \\ Bronwen Morrell \\ BA(Hons), \\ Research Academic, \\ Rowena Forsyth \\ BA(Hons), PhD Post-doctoral Fellow, \\ lan Kerridge \\ BMed(Hons) \\ FRCPA, FRACP, \\ Associate Professor \\ and Director \\ Cameron Stewart \\ BEcLLB(Honsl), PhD, \\ FACLM(Hons) \\ Professor, ${ }^{2}$ and Director ${ }^{3}$ \\ 1 School of Public Health, University of Sydney, \\ Sydney, NSW. \\ 2 Centre for Values, Ethics \\ and the Law in Medicine \\ University of Sydney, \\ Sydney, NSW. \\ 3 Centre for Health Law, Ethics and Clinical \\ Governance, University of \\ Sydney, Sydney, NSW. \\ simon.chapman@ sydney.edu.au}

MJA 2012; 196: 452-456 doi: 10.5694/mjall.11224
U niversities and research institutes encourage staff to develop relationships with government agencies, the private sector and non-government organisations. These relationships often involve financial support to universities and individual researchers in research and equipment grants, travel and conference support, and unrestricted educational grants, where support is given to researchers to increase the flow of information to the public or relevant professions. While such associations may benefit universities and researchers, they may also influence the principal functions of universities (to educate, to generate knowledge and to provide social benefit); influence the design and outcomes of research, and thereby distort the scientific record; threaten the core values of scholarly independence; influence public discourse and the development of public policy; and undermine public trust in the integrity of science and research. ${ }^{1}$

Because of these concerns, research institutions (following academic journals) have adopted policies on competing interests over the past two decades. The extent of staff compliance with these policies and their impact are largely unknown. Similarly, little is known about how accessible these policies are to the public. This is important because most research is published in subscriptiononly journals, which are largely inaccessible to the public and the media. While news media frequently report on the work or views of researchers, information about researchers' competing interests is mostly absent in news reports, ${ }^{2}$ reflecting both time and space constraints in the media ${ }^{3}$ and the difficulty that journalists face in learning about researchers' compet-

Objectives: To document the existence and provisions of Australian universities' policies on the competing interests of academic staff and university practices in recording, updating and making these declarations publicly accessible.

Design and setting: A 14-item survey was sent to the vice-chancellors of 39 Australian universities and university websites were searched for relevant policies.

Results: Twelve universities declined to provide any information. Of the 27 that did, all had policies on staff competing interests. Fifteen did not require regular declarations from staff and only four required annual declarations. Eight universities maintained a centralised register of COls of all staff and six had a mechanism in place that allowed members of the public to access information on COIs. None reported that they required that staff place their COI declarations on their website profiles and none had policies that indicated that staff should declare COls when making a public comment.

Conclusions: Australian universities vary significantly in their approaches to the declaration and management of competing interests. While two-thirds of Australian universities require staff to declare competing interests, this information is mostly inaccessible to the public. Australian universities should adopt a standard approach to the declaration and management of competing interests and commit to meaningful transparency and public accountability. This could include frequently updated declarations on website profiles of all staff. In addition, dialogue about what is needed to effectively deal with competing interests should be encouraged.

ing interests. Although recommendations on making data on academicindustry relationships publicly available on institutional websites have been made in the United States, no such steps have been taken by Australian universities. ${ }^{4}$

We aimed to establish how interested parties could determine whether a researcher in an Australian university had competing interests and how accessible such information was to the public, including journalists. Our study complements a 2009 study of all 20 Australian medical schools' policies on competing interests ${ }^{5}$ by considering whole-ofuniversity policies and practices.

\section{Methods}

Ethics approval was obtained from the University of Sydney Human
Research Ethics Committee. In July 2010, the vice-chancellors of all 39 Australian universities were invited to complete a 14-item survey on policies and practices on the competing interests of academic staff. Three reminder letters were sent, each listing the universities that had replied. Also, each responding university's website was searched for relevant policies, and any that included reference to conflict of interest (COI) were included in the analysis.

\section{Results}

Responses were received from 27 universities; three responses were incomplete (Charles Darwin University, Macquarie University, RMIT University) but these were included in the analysis. Of those that responded, 26 universities (hereafter 


\begin{tabular}{|c|c|c|c|c|c|c|}
\hline & $\begin{array}{l}\text { General policies and/or } \\
\text { guidelines with explicit COI } \\
\text { clause (number) }\end{array}$ & $\begin{array}{l}\text { Specific COI } \\
\text { policies } \\
\text { (number) }\end{array}$ & $\begin{array}{l}\text { Centralised } \\
\text { register for all } \\
\text { staff }\end{array}$ & $\begin{array}{l}\text { Centralised } \\
\text { register for } \\
\text { senior staff only }\end{array}$ & $\begin{array}{l}\text { Centralised } \\
\text { register for certain } \\
\text { types of COI }\end{array}$ & $\begin{array}{l}\text { Decentralised } \\
\text { registers only }\end{array}$ \\
\hline Australian Catholic University & $Y(2)$ & $\mathrm{N}$ & $\mathrm{N}$ & $N$ & $\mathrm{~N}$ & $N$ \\
\hline Australian National University & $Y(2)$ & $Y(1)$ & $\mathrm{N}$ & $\mathrm{N}$ & $\mathrm{N}$ & N \\
\hline Charles Darwin University & $Y(1)$ & $\mathrm{N}$ & $\mathrm{N}$ & $\mathrm{N}$ & $\mathrm{N}$ & N \\
\hline Charles Sturt University & $Y(1)$ & $Y(1)$ & $\mathrm{N}$ & $\mathrm{N}$ & $\mathrm{N}$ & N \\
\hline Curtin University & $Y(2)$ & $Y(1)$ & $\mathrm{Y}$ & $\mathrm{N}$ & $\mathrm{N}$ & $\mathrm{N}$ \\
\hline Deakin University & $Y(3)$ & $Y(2)$ & $\mathrm{N}$ & Y & $\mathrm{N}$ & $\mathrm{N}$ \\
\hline Edith Cowan University & $Y(2)$ & $\mathrm{N}$ & $\mathrm{N}$ & $\mathrm{N}$ & $\mathrm{N}$ & $\mathrm{N}$ \\
\hline La Trobe University & $Y(2)$ & $\mathrm{N}$ & $\mathrm{Y}$ & N & N & $\mathrm{N}$ \\
\hline Macquarie University & $Y(1)$ & $\mathrm{N}$ & N & Y & N & $\mathrm{N}$ \\
\hline Monash University & $\mathrm{N}$ & $Y(2)$ & N & N & Y & $\mathrm{N}$ \\
\hline Murdoch University & $Y(2)$ & $Y(1)$ & N & N & $\mathrm{N}$ & Y \\
\hline Queensland University of Technology & $Y(2)$ & $Y(1)$ & N & N & Y & $\mathrm{N}$ \\
\hline RMIT University & $Y(1)$ & $Y(3)$ & Y & N & $\mathrm{N}$ & $\mathrm{N}$ \\
\hline University of Adelaide & $N$ & $Y(2)$ & N & N & $\mathrm{N}$ & $\mathrm{N}$ \\
\hline University of Canberra & $Y(4)$ & $\mathrm{N}$ & $\mathrm{N}$ & Y & $\mathrm{N}$ & N \\
\hline University of Melbourne & $Y(4)$ & $\mathrm{N}$ & $\mathrm{N}$ & $\mathrm{N}$ & $\mathrm{N}$ & N \\
\hline University of New England & $Y(2)$ & $\mathrm{N}$ & Y & $\mathrm{N}$ & $\mathrm{N}$ & N \\
\hline University of New South Wales & $Y(3)$ & $Y(1)$ & Y & $\mathrm{N}$ & $\mathrm{N}$ & N \\
\hline University of Notre Dame Australia & $Y(1)$ & $\mathrm{N}$ & $\mathrm{N}$ & $\mathrm{N}$ & $\mathrm{N}$ & N \\
\hline University of Queensland & $Y(4)$ & $\mathrm{N}$ & $\mathrm{N}$ & $\mathrm{N}$ & $\mathrm{N}$ & N \\
\hline University of Southern Queensland & $Y(3)$ & $\mathrm{N}$ & N & N & $\mathrm{N}$ & N \\
\hline University of the Sunshine Coast & $Y(2)$ & $\mathrm{N}$ & $\mathrm{N}$ & N & $\mathrm{N}$ & N \\
\hline University of Sydney & $Y(4)$ & $Y(1)$ & Y & N & $\mathrm{N}$ & N \\
\hline University of Western Australia & $Y(4)$ & $\mathrm{N}$ & $\mathrm{N}$ & $\mathrm{N}$ & $\mathrm{N}$ & N \\
\hline University of Western Sydney & Y (4) & $\mathrm{N}$ & Y & $\mathrm{N}$ & $\mathrm{N}$ & N \\
\hline Victoria University & $Y(3)$ & $\mathrm{N}$ & Y & $\mathrm{N}$ & $\mathrm{N}$ & N \\
\hline $\begin{array}{l}\text { Total number of universities (total number of policies } \\
\text { and/or guidelines) }\end{array}$ & $24(59)$ & $17(16 *)$ & 8 & 3 & 2 & 7 \\
\hline Average number of policies and/or guidelines & 2.36 & 0.64 & - & - & - & - \\
\hline
\end{tabular}

referred to as participating universities) provided copies of their COI (or related) policies and the other (Bond University) reported that it had a COI policy. Three universities declined to participate (Flinders University, University of Newcastle, University of South Australia). The remaining nine universities did not acknowledge receipt of the survey or respond (CQUniversity, Griffith University, James Cook University, Southern Cross University, Swinburne University of Technology, University of Ballarat, University of Tasmania, University of Technology Sydney, University of Wollongong).

\section{COI policies and registers}

Of the 26 participating universities, 24 advised that they had a general policy and/or guidelines that addressed COI of staff (Box 1) and 11 had one or more specific COI policies (ie, policies in which COI was the core topic). Fifteen universities did not have a specific COI policy but instead had at least one policy and/or guideline that addressed COI of staff. Of these 15, four stated that they were in the process of developing a specific COI policy.

All 26 participating universities had policies or guidelines (either general or specific) stating that staff must declare COIs to the university. These policies variously indicated that declarations were to be made to the: staff member's supervisor or senior manager (14 universities), head of department (four), deputy vice-chancellor (two), dean (one), or an unspecified member of the university (two). In four universities, the person to whom declarations were to be made varied depending on the type of COI or the position of the staff member.

Fifteen of the 26 participating universities required staff to make declarations once or only as perceived COIs arose and did not require regular reports from all staff (Charles Darwin University, Macquarie University and RMIT University did not respond to this survey item, so their data were determined by policy analysis). Four universities required that all staff make annual declarations (Charles Sturt University, Murdoch University, University of Sydney, University of Western Sydney), two required annual declarations by senior 


\begin{tabular}{|c|c|c|c|c|c|c|c|c|}
\hline & Declare & Withdraw* & $\begin{array}{l}\text { Assess if } \\
\text { COl exists }\end{array}$ & $\begin{array}{c}\text { Seek } \\
\text { advice }\end{array}$ & $\begin{array}{l}\text { Management } \\
\text { plan }\end{array}$ & $\begin{array}{l}\text { Reorganise } \\
\text { or reassign }\end{array}$ & $\begin{array}{c}\text { Refer to a } \\
\text { specific body }\end{array}$ & $\begin{array}{l}\text { Notify interested } \\
\text { parties }\end{array}$ \\
\hline Australian Catholic University & $\mathrm{Y}$ & $\mathrm{N}$ & $\mathrm{N}$ & $\mathrm{N}$ & $\mathrm{N}$ & $\mathrm{N}$ & $\mathrm{N}$ & $\mathrm{N}$ \\
\hline Australian National University & Y & $\mathrm{N}$ & $\mathrm{N}$ & $\mathrm{N}$ & $\mathrm{N}$ & $\mathrm{N}$ & $\mathrm{N}$ & $\mathrm{N}$ \\
\hline Charles Darwin University & Y & $\mathrm{N}$ & $\mathrm{N}$ & $\mathrm{N}$ & $\mathrm{N}$ & $\mathrm{N}$ & $\mathrm{N}$ & N \\
\hline Charles Sturt University & Y & $\mathrm{Y}$ & $\mathrm{N}$ & $\mathrm{N}$ & Y & $\mathrm{N}$ & $\mathrm{N}$ & $\mathrm{Y}$ \\
\hline Curtin University of Technology & Y & Y & Y & $\mathrm{N}$ & Y & $\mathrm{N}$ & $\mathrm{N}$ & N \\
\hline Deakin University & Y & Y & Y & $\mathrm{N}$ & Y & Y & $N$ & $\mathrm{~N}$ \\
\hline Edith Cowan University & Y & $N$ & $\mathrm{~N}$ & $N$ & $\mathrm{~N}$ & $\mathrm{~N}$ & $\mathrm{~N}$ & Y \\
\hline La Trobe University & Y & Y & $\mathrm{N}$ & $\mathrm{N}$ & Y & $\mathrm{N}$ & $\mathrm{N}$ & $\mathrm{N}$ \\
\hline Macquarie University & Y & $\mathrm{N}$ & $\mathrm{N}$ & Y & $\mathrm{N}$ & $\mathrm{N}$ & $\mathrm{N}$ & $\mathrm{N}$ \\
\hline Monash University & Y & $\mathrm{N}$ & Y & $\mathrm{N}$ & Y & $\mathrm{N}$ & Y & $\mathrm{N}$ \\
\hline Murdoch University & Y & Y & $\mathrm{N}$ & $\mathrm{N}$ & $\mathrm{N}$ & $\mathrm{N}$ & $\mathrm{N}$ & $\mathrm{N}$ \\
\hline Queensland University of Technology & Y & Y & Y & $\mathrm{N}$ & Y & $\mathrm{N}$ & $\mathrm{N}$ & $\mathrm{N}$ \\
\hline RMIT University & Y & Y & $\mathrm{N}$ & $\mathrm{N}$ & Y & Y & $\mathrm{N}$ & $\mathrm{N}$ \\
\hline University of Adelaide & Y & Y & Y & $N$ & Y & Y & $\mathrm{N}$ & $\mathrm{N}$ \\
\hline University of Canberra & Y & $\mathrm{N}$ & Y & Y & $\mathrm{N}$ & $\mathrm{N}$ & $\mathrm{N}$ & $\mathrm{N}$ \\
\hline University of Melbourne & Y & $\mathrm{N}$ & $\mathrm{N}$ & $\mathrm{N}$ & Y & $\mathrm{N}$ & $\mathrm{N}$ & N \\
\hline University of New England & Y & Y & $\mathrm{N}$ & $\mathrm{N}$ & $\mathrm{N}$ & $\mathrm{N}$ & $\mathrm{N}$ & N \\
\hline University of New South Wales & Y & $\mathrm{N}$ & Y & $\mathrm{N}$ & $\mathrm{Y}$ & $\mathrm{N}$ & Y & $\mathrm{N}$ \\
\hline University of Notre Dame Australia & Y & $\mathrm{N}$ & $\mathrm{N}$ & $\mathrm{N}$ & Y & $\mathrm{N}$ & $\mathrm{N}$ & N \\
\hline University of Queensland & Y & $\mathrm{N}$ & $\mathrm{N}$ & $\mathrm{N}$ & $\mathrm{N}$ & $\mathrm{N}$ & $\mathrm{N}$ & $\mathrm{N}$ \\
\hline University of Southern Queensland & Y & Y & $\mathrm{N}$ & $\mathrm{N}$ & $\mathrm{N}$ & $\mathrm{N}$ & $\mathrm{N}$ & $\mathrm{N}$ \\
\hline University of the Sunshine Coast & Y & $\mathrm{N}$ & $\mathrm{N}$ & Y & $\mathrm{N}$ & $\mathrm{N}$ & $\mathrm{N}$ & $\mathrm{N}$ \\
\hline University of Sydney & Y & Y & Y & Y & Y & Y & $\mathrm{N}$ & Y \\
\hline University of Western Australia & Y & Y & Y & $\mathrm{N}$ & $\mathrm{N}$ & $\mathrm{N}$ & $\mathrm{N}$ & Y \\
\hline University of Western Sydney & Y & Y & $\mathrm{N}$ & $\mathrm{N}$ & Y & $\mathrm{N}$ & Y & Y \\
\hline Victoria University & Y & $\mathrm{N}$ & $\mathrm{N}$ & $\mathrm{N}$ & $\mathrm{N}$ & $\mathrm{N}$ & $\mathrm{N}$ & $\mathrm{N}$ \\
\hline Total number of universities & 26 & 13 & 9 & 4 & 13 & 4 & 3 & 5 \\
\hline
\end{tabular}

staff only (Deakin University, University of New South Wales) and one stated in its survey response that it required biennial declarations by all staff (Australian National University) but no statement could be found to this effect in its policies. Three required that only staff who had previously reported a COI provide an annual declaration. One university (University of Western Australia) required declarations with differing regularity depending on the nature of the COI and the position of the staff member.

Specific policies regarding the receipt of gifts and services were found on the websites of 23 of the participating universities. Generally, these policies stated that staff could accept gifts of a nominal value as long as these would not, and would not be seen to, create a COI. Almost all universities identified a specific sum above which the gift must be relinquished and/or declared, with this figure ranging from $\$ 25$ to $\$ 300$. Three universities specified different approaches depending on the value of the gift: items under a certain value - \$100 (University of Sydney, University of the Sunshine Coast) or $\$ 150$ (Curtin University of Technology) - were considered to be of nominal value and could be retained by the staff member, whereas items of a higher value could only be retained if first reported (\$100 or more, University of Sydney), if a partial payment for the gift is made (\$250 or more, University of the Sunshine Coast; staff can be given the option of paying to the university the difference between the gift's value and the $\$ 250$ threshold) or if approved by the vice-chancellor or executive manager (\$300 or more, Curtin University of Technology).
Fourteen of the participating universities maintained some form of register of staff declarations (Box 1). Eight maintained a centralised register of the declarations of all staff, three kept a register of COIs for senior staff only, two had a register for certain types of COIs and one kept decentralised registers with each department or school. Twelve had no register.

About half the participating universities noted that COIs should be declared to publishers (14 universities) and funding bodies (13). In no instances were staff required to make the declarations required by these bodies and, in almost all cases, guidance was not provided on when declarations to publishers and funding bodies would be appropriate.

Although all 26 participating universities required that staff declare COIs, only two of 21 universities that 
responded to the survey item on auditing (Curtin University of Technology and University of Queensland) reported that they had conducted an audit of staff compliance with their COI policies in the previous 5 years. It was not possible to assess of the adequacy of these audits.

\section{Management of failure to declare COIs}

Seventeen of the participating universities had policies regarding the management of staff who had not declared a competing interest. These were general misconduct policies, rather than policies designed specifically to deal with failure to declare COIs.

\section{Transparency and public accessibility of COI declarations}

Of 25 universities that responded to the survey item on whether staff were required to place declarations on their website profiles, none had this as a requirement. Of those 13 universities with a centralised register of staff declarations, 12 responded to the item on whether this register was publicly accessible without the need for a freedom-of-information application. Of these, none published their register on the internet, two made the list available on request (University of Southern Queensland and University of Western Sydney) and three provided access to declarations made by a specific staff member on request (LaTrobe University, University of Canberra, University of New South Wales). The External Interests Policy of the University of Sydney states that people with grounds to inspect the conflicts register will be permitted access to it at the discretion of the General Counsel but does not define what constitutes valid grounds for access.

Thus, while the policies of all 26 participating universities required staff to declare perceived COIs, only six universities provided a mechanism by which members of the public might be able to access this information on application. Notably, policies of 11 universities stated that information regarding COIs that staff provided would remain confidential, while policies of two universities provided a further measure to protect staff privacy by requiring staff to simply notify the university that a conflict existed without providing details of the conflict, on the understanding that staff would withdraw from the financial or personal situation causing the conflict or withdraw from the university duties that were potentially compromised.

Although we found public comment policies for 21 universities, none required that staff declare potential COIs to media when making a public comment.

\section{Institutional management of COIs}

Five of the participating universities appeared to require nothing more than the declaration of a perceived COI and provided no guidance on how COIs should be managed beyond this (Box 2). While two universities (Macquarie University and University of the Sunshine Coast) simply stated that staff should "seek advice" regarding conflicts of interest, 19 universities provided some degree of guidance regarding the management of COIs. Three universities' policies stated that the individual must withdraw from either the financial or personal situation causing the conflict, or from university duties that were potentially compromised, and did not provide further advice. Two indicated that on receipt of a declaration, a determination would be made as to whether a conflict existed and advice would be sought from a relevant authority. The policies of 13 universities indicated that once a COI had been declared, a management plan must be put in place. In some cases where a management plan was to be put in place, strategies for managing declared COIs were outlined. These included withdrawal of the staff member from the interest generating the conflict or the university activity that might be compromised by the conflict (nine universities); reorganisation or reassignment of university activities such that the potential for conflict is minimised (four); referral of the matter to a specific body for advice (three); and notification of publishers, funding bodies and other interested parties (three).

\section{Discussion}

Our survey of Australian universities showed significant variance in approaches to dealing with competing interests and significant deficiencies in policies and practices surrounding COIs. The major issues that we identified were: lack of clarity regarding what should be declared and the frequency of declarations; absence of clear guidance regarding the management of competing interests; few attempts to audit compliance with COI policies; no guidance on the implications of non-compliance; and reluctance to maintain and make publicly available registers of competing interests.

Information about the competing interests of Australian academics and researchers is almost totally inaccessible to the public and is not open to media scrutiny. This is particularly problematic as it undermines the moral justification for COI policies and may erode public trust rather than reinforce it.

Concerns about breaching staff privacy seem to be at the heart of why Australian universities do not make information on competing interests public. As such interests could include details of shareholdings, income received, family and business trusts, and direct and indirect forms of financial and other support from companies, it might be argued that staff have rights to keep such information private. But do they have such rights and, if so, do these rights override the right of the public to know about competing interests relating to research?

Australian privacy law is a patchwork of judge-made law, federal legislation and state legislation. ${ }^{6}$ Much needs to be done to address this confusing overlap of regulation, but all of these regimes allow for disclosure of private information when the person has agreed to the information being disclosed. One way around these difficulties would therefore be to make it a condition of employment that researchers consent to making declarations of competing interests and be subject to a standard university policy of declaration, audit and enforcement. Alternatively, there is potential for disclosure without 
consent as the legislative regimes allow for disclosure of private information for the investigation of improper or unlawful conduct. In using such methods, care would have to be taken in determining when and how coercive disclosures should occur. Arguably, if universities were keen to harbour and foster a culture of open disclosure among staff, they would need to be very careful to use coercive measures fairly because of the risk that staff distrust might cause the system to break down.

We believe that Universities Australia or the Australian Government Department of Education, Employment and Workplace Relations should implement a uniform approach to the disclosure of COIs in Australian universities.

Most Australian universities have publicly accessible staff directories on their websites where the name, contact details, research interests, publications and other achievements of staff are listed and regularly updated. Australian universities should implement standard reporting templates whereby each staff member's website profile includes a mandatory section showing all competing interests (as is already done for parliamentarians), that is updated frequently. Objections about breaches of privacy could be met by enabling staff to opt for either full disclosure or partial disclosure that allows non-specific declaration of competing interests in cases where the university accepts that a breach of privacy outweighs the public interest of full disclosure (eg, declaration of family trusts or shareholdings deemed to be of no relevance to a staff member's research).

Research in Australian universities is a publicly funded exercise and the public has a right to know when an Australian university researcher has competing interests that may influence their research or judgement. Unless a standard approach is taken to these issues, Australian universities will continue to have a haphazard approach to declaring, managing and policing COIs. Encouragement of further dialogue about what is needed to effectively deal with com- peting interests and implementation of clear, uniform national approaches to competing interests will help to maintain public confidence in research and improve reporting on research progress in Australia.

Acknowledgements: This study was funded by a National Health and Medical Research Council grant (63284). The NHMRC had no role in the study design, data collection and analysis, decision to publish, or preparation of the manuscript.

Competing interests: No relevant disclosures.

Received 23 Sep 2011, accepted 13 Feb 2012.

1 Gurney S, Sass J. Public trust requires disclosure of potential conflicts of interest. Nature 2001; 413: 565.

2 Moynihan R, Bero L, Ross-Degnan D, et al. Coverage by the news media of the benefits and risks of medications. NEngl J Med 2000; 342: 1645-1650.

3 Chapman S, Holding SJ, Ellerm J, et al. The content and structure of Australian television reportage on health and medicine, 2005-2009: parameters to guide health workers. Med J Aust 2009; 191: 620-624.

4 Campbell EG, Zinner DE. Disclosing industry relationships - toward an improved federal research policy. N Engl J Med 2010; 363: 604-606.

5 Mason PR, Tattersall MH. Conflicts of interest: a review of institutional policy in Australian medical schools. Med J Aust 2011; 194: 121-125.

6 Australian Law Reform Commission. For your information: Australian privacy law and practice (ALRC Report 108). Sydney: ALRC, 2008. 